\title{
Os cuidados da Estratégia Saúde da Família a um adolescente vítima de bullying: uma cartografia
}

\author{
Mapping the provision of care to an adolescent victim of school \\ bullying by the Family Health Strategy in Brazil
}

Pamela Lamarca Pigozi (https://orcid.org/0000-0003-0193-924X) ${ }^{1}$

Ana Lúcia Machado (https://orcid.org/0000-0003-4240-3441) ${ }^{1}$

${ }^{1}$ Escola de Enfermagem, Universidade de São Paulo. Av. Dr. Enéas Carvalho de Aguiar 419, Cerqueira César. 05403-000 São Paulo SP Brasil.pamelapigozi@usp.br

\begin{abstract}
The provision of care to adolescents who are victims of bullying is necessarily intersectoral and, as such, goes beyond the limits of the school context. Underpinned by this principle, this study mapped the care provided to an adolescent victim of bullying by the Family Health Strategy, using cartography to elaborate an analytical flow chart of the pathway taken by the patient through the health service. The care maps produced by the health professionals involved in the process showed that care was out of step, dry and had a low level of resolvability. Despite these findings, the use of this instrument allowed the health team to propose other forms of support for the adolescent. After visualizing the pathway taken by the patient through the care network, the team was able to rethink limiting approaches to health care and discover other care possibilities that go beyond physical dimensions. The care provided by the Family Health Strategy was shown to be inconsistent. However, the mapping activity clearly showed that primary care services play a crucial role in providing appropriate support to adolescent victims of bullying and breaking the cycle of violence.
\end{abstract}

Key words Adolescent health, Bullying, Intersectoral action, Cartography, Primary health care
Resumo O cuidado ao adolescente envolvido em situações de "bullying" é necessariamente intersetorial, de tal modo que ultrapassa os limites do cenário escolar e amplia-se para o setor da saúde. Partindo desse princípio, este estudo buscou cartografar a produção do cuidado ofertada a um adolescente em situações de "bullying" pela Estratégia Saúde da Família. Para tal fim, foi utilizado o método da cartografia, através do fluxograma analisador e do diário de campo. Deste modo, mapas do cuidar foram produzidos pelos profissionais de saúde, entretanto esse cuidar mostrou-se descompassado, árido e pouco resolutivo. Apesar disso, através do uso dos instrumentos de pesquisa, foi possivel inaugurar outras formas de amparo ao adolescente. A equipe, ao visualizar seu trajeto em busca de suporte, repensou modos engessados de fazer saúde e, assim, tornou-se possivel produzir um cuidado com outras possibilidades de vida, para além do aspecto biológico. A atenção à saúde do adolescente envolvido com o "bullying" mostrou-se oscilante na Estratégia Saúde da Família. No entanto, por meio da cartografia, ficou evidente o papel crucial da atenção primária em suportar o adolescente, o que poderia contribuir para a cessação do ciclo da violência.

Palavras-chave Saúde do adolescente, "Bullying", Intersetorialidade, Cartografia, Atenção primária. 


\section{Introdução}

O bullying é caracterizado como um conjunto de comportamentos agressivos que acontece repetidas vezes e com desequilíbrio de poder entre os envolvidos, de modo que a vítima se sente impotente perante o ato de violência. Vale ressaltar que casos isolados de violência não são definidos como bullying, portanto, para configurá-lo como tal, é necessário que haja intencionalidade em agredir sem motivação aparente ${ }^{1,2}$.

No Brasil, a ocorrência desse problema no ambiente escolar é significativa. Moura et al. ${ }^{3}$ demonstraram, através de um estudo transversal com 1.075 escolares, que $17,6 \%$ deles eram alvos de bullying. Já, de acordo com Fisher ${ }^{4}$, pelo menos $10 \%$ dos estudantes relataram ter sido vitimizados três ou mais vezes no mesmo ano. De modo complementar, outro extenso estudo nacional - a Pesquisa Nacional de Saúde do Escolar (PeNSE), realizada com 109.104 escolares em todas as capitais brasileiras - demonstrou que $20,8 \%$ dos estudantes relataram ser autores, enquanto $7,2 \%$ disseram ser alvos de bullying 5 .

A terceira edição do estudo (PeNSE) ${ }^{6}$, além de demonstrar que $19,8 \%$ dos estudantes relataram ser autores da agressão, sugere também que $\mathrm{o}$ ato de praticar bullying pode estar relacionado a algumas características dos adolescentes, como sentir-se sozinho, ter insônia e possuir poucos amigos. Além disso, apanhar da família e faltar às aulas sem comunicar a seus responsáveis pode estar associado à prática desta violência. Adicionalmente, o adolescente vitimizado também pode apresentar algumas características quando envolvido com esta problemática, como, por exemplo, baixo redimento escolar, não desejar ir para a escola, insegurança no ambiente escolar, medo, ansiedade, tristeza, depressão, cefaléia, desmaio, tentativa de suicídio e suicídio ${ }^{7}$.

Em geral, estudos apontam para um problema de saúde pública que afeta diretamente a saúde psíquica e física dos escolares ${ }^{8}$, além de ser um assunto complexo que requer empenho intersetorial e não somente escolar ${ }^{9,10}$. Nesse sentido, os profissionais de saúde podem estar atentos aos sinais de violência evidenciados pelos adolescentes, e assim poderem intervir precocemente ${ }^{7}$.

No Brasil, a Atenção Primária pode ser representada pela Estratégia Saúde da Família (ESF). Esse modelo de atenção à saúde é responsável por construir relações de vínculo com os usuários adscritos em seu território de abrangência e ser resolutivo quanto às suas demandas de saúde. Tais fundamentos e diretrizes garantem a continuidade das ações e a longitudinalidade do cuidado. A ESF, através do acolhimento e escuta sensível, pode resolver grande parte dos problemas apresentados em sua comunidade. Ademais, o serviço deve estar atento não somente aos problemas de ordem física, mas também às questões da esfera psicossocial que acomentem os jovens, como, por exemplo, a prevenção das violências ${ }^{11}$.

Desse modo, o presente estudo buscou compreender como o cuidado ofertado ao adolescente vítima de bullying ocorre na Estratégia Saúde da Família. Tal estudo busca captar, através da perspectiva dos profissionais de saúde, quais foram os caminhos percorridos pelo adolescente em busca de amparo dentro da própria rede de atenção à saúde, sendo que a atenção básica, bem como o serviço ambulatorial e hospitalar, podem colaborar na construção desses mapas no território. Nesse sentido, pretendeu-se cartografar a produção do cuidado ofertada ao adolescente em situações de bullying na atenção primária.

\section{Metodologia}

O referencial metodológico utilizado foi a cartografia, a qual é baseada na esquizoanálise deleuziana e guattariana, umas das correntes da Análise Institucional ${ }^{12}$. O que será apresentado é a construção coletiva e transitória de vários sujeitos constituídos por suas histórias, seus contextos de trabalho, suas experiências e vivências tão genuínas, singulares e mutáveis.

Esse método torna possível acompanhar a processualidade dos acontecimentos, assim como os caminhos percorridos pelos sujeitos e suas relações com o ambiente em que transitam. Permite também acompanhar o desejo como força disparadora de processos de cuidado, a reprodução ou produção de hábitos propulsores ou não de vida, encontros de alta ou baixa potência criativa entre os sujeitos nos seus diversos cenários de passagem.

A cartografia "requer a habitação de um território"13. Este que não se configura pela sua funcionalidade ou utilidade, como, por exemplo, evidenciar a função da escola ou do serviço de saúde, contudo privilegia os modos de sentir e expressar dos diversos atores ali envolvidos. Tais territórios podem ser compostos por linhas instituídas, ou seja, que engessam ou reproduzem o cuidado, e pelas linhas instituintes, que são aquelas mais flexíveis ou de fuga que dão passagem para inúmeras formas criativas e inventivas de cuidar $^{14,15}$. 
A produção dos dados ocorre no instante da efetivação do dispositivo, em ato. O Fluxograma Analisador de Merhy ${ }^{16}$, empregado neste estudo, é um intrumento de pesquisa que pode ser trabalhado como um dispositivo. Será usado com a intenção de engendrar estratégias que produzem um modo de ver, não o ver calcado nas imagens clichês, não ver para avaliar uma situação a fim de nela intervir, não é um "ver para fazer”, como diz Pelbart ${ }^{17}$, mas um "ver para enxergar aquilo que não é visível, ver para captar da realidade sua dimensão de excesso, de beleza, de horror, de intolerável, de assustador"17.

Tal instrumento de pesquisa pode criar espaços estimulantes ao relato das cenas; o despertar para um pensar diferente; refazer e reconstruir diálogos; refletir e discutir minúcias difíceis, dolorosas ou não; imaginar e elencar o que se passou antes e o que se passará ou se passou depois das cenas trazidas ${ }^{18}$.

O fluxograma analisador do modelo de atenção de um serviço de saúde é um diagrama utilizado com "a perspectiva de desenhar um certo modo de organização de um conjunto de processos de trabalho, que se vinculam entre si em torno de uma certa cadeia de produção" ${ }^{16}$. Tal estrutura pode apresentar graficamente o modo de trabalhar de uma equipe, elaborado de forma usuário-centrado, com riqueza de detalhes, para perceber os aspectos da micropolítica da organização de trabalho e da produção de serviços ${ }^{16}$.

Esse instrumento pretende apreender cinco ações que são representadas graficamente por três diferentes símbolos: a elipse, como entrada e saída do processo de produção de serviços; o losango, que indica momentos de decisão para a continuidade do trabalho; e o retângulo, que marca o momento de intervenção, de ação sobre o processo $^{18}$ (Figura 1).

Para exemplificar, no caso deste estudo, a trajetória de Teo (nome fictício), o qual foi o sujeito do caso traçador no serviço de saúde, foi esmiuçada no fluxograma: como ele entrou, por quem foi recebido, por que ele entrou, por que ficou, quais foram os cuidados e as decisões direcionadas a ele, bem como quem estava com ele, como Teo participou desse processo e também como os profissionais de saúde, em um agir conjunto, cuidaram do adolescente. O objetivo principal dessa ferramenta é disparar um processo de coletivização do trabalho.

O desafio consiste em realizar um diagnóstico do trabalho cotidiano e traduzi-lo para um formato que seja visível e partilhável por todos, para que, com base nele, possam ser traçadas al- gumas intervenções que se mostrem necessárias e viáveis ${ }^{18}$.

$\mathrm{O}$ adolescente escolhido como caso traçador estava envolvido em situações de bullying e também era atendido pela ESF. Teo começou a ser vitimizado no ambiente escolar quando todos os pelos de seu corpo caíram, em razão de uma alopecia total. Esse também foi um dos principais motivos pelos quais sua mãe procurou ajuda no serviço de saúde.

O grupo tinha a conformação básica de uma equipe de ESF, composta por uma enfermeira, um médico, dois auxiliares de enfermagem, seis Agentes Comunitários de Saúde (ACSs) e uma recepcionista ${ }^{11}$. Participaram quase todos, com exceção de uma auxiliar que não pôde deixar as atividades da unidade; dos seis ACSs somente uma pôde participar, pelo mesmo motivo. Além disso, a equipe preferiu priorizar a participação da ACS que conhecia o caso traçador. No total, foram cinco participantes que constituíram o grupo para a realização da atividade.

A atividade do fluxograma não foi gravada, pois todo o processo foi descrito pelos cinco integrantes (enfermeira, auxiliar de enfermagem, recepcionista, ACS e médico) e desenhado em duas folhas de flipchart coladas em uma parede no sentido horizontal para melhor elaboração do traçado. O diário de campo foi utilizado antes e depois para anotação de tudo o que foi percebido para além do que estava anotado no flipchart. A atividade do fluxograma ocorreu em um encontro com duração de 90 minutos.

Somado a isto, toda a atividade foi acordada com o adolescente e a equipe de saúde, respeitando a ética e o sigilo dos participantes.

Este estudo é parte de uma Tese de Doutorado, na qual outros instrumentos de pesquisa foram utilizados em diferentes cenários. Neste artigo será discutido apenas o uso do Fluxograma Analisador com os profissionais de saúde.

\section{Os traçados de Teo}

Durante a atividade, a ACS, a recepcionista e a enfermeira participaram ativamente, o médico, razoavelmente, e a auxiliar de enfermagem, bem pouco.

\section{A entrada}

No momento em que se deu a pesquisa, Teo estava com 11 anos de idade. Seu acesso (entrada) não ocorreu diretamente pela porta de entrada da ESF e sim por intermédio da ACS responsável por aquela área adscrita. 


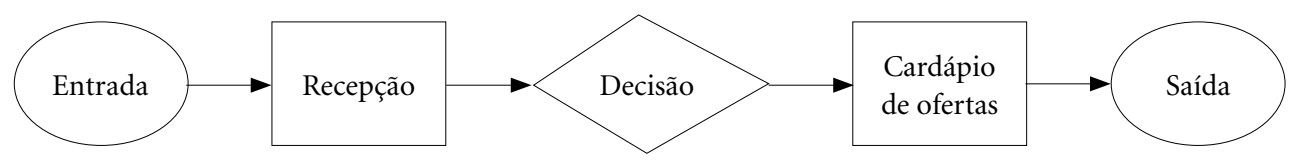

Figura 1. Exemplo de fluxograma analisador.

Fonte: Franco TB. Fluxograma descritor e projetos terapêuticos para análise e serviço de saúde, em apoio ao planejamento: o caso de luz (MG). In: Merht EE et al. O trabalho em saúde: olhando e experienciando o SUS no cotidiano. São Paulo: Hucitec, 2003.

Emília (nome fictício da mãe de Teo), que caminhava no bairro, solicitou a ACS um atendimento breve ao seu filho na ESF, pois Teo estava quase sem nenhum pelo no corpo, incluindo os cabelos, os quais começaram a cair abruptamente, sem motivo aparente. Complementou que o filho não estava bem emocionalmente e que seu rendimento escolar estava caindo; Teo recusavase a ir para a escola devido ao bullying que sofria, praticado pelos colegas de classe (pelo fato de ele não ter pelos).

Mari (ACS) compreendeu a gravidade da situação e Teo foi atendido brevemente em consulta de enfermagem com a enfermeira Paula.

\section{A recepção}

Teo e sua mãe foram acolhidos pela enfermeira Paula. A profissional o acolheu e entendeu a necessidade de atendimento médico. Foi feito um encaixe no mesmo momento. $\mathrm{O}$ prontuário de Teo foi separado pela recepcionista e encaminhado à triagem para aferição de pressão arterial, peso e altura.

\section{A decisão}

Teo e sua mãe foram recebidos pelo médico João, que realizou breve anamnese e exame físico. O médico o diagnosticou com alopecia total por motivo desconhecido e também com criptorquidia (retenção de testículos na cavidade abdominal). O estado emocional de Teo não foi mencionado.

\section{Cardápio de ofertas}

Teo foi encaminhado para a urologia e dermatologia do município. Na confecção do fluxograma o médico não relatou muitos detalhes do atendimento e mostrou-se um pouco à margem do problema.
A enfermeira, com o encaminhamento em mãos, dirigiu-se diretamente ao agendamento de especialidades, pois inferiu que o médico do município não trataria da alopecia total. Logo, Emília e Teo foram a São Paulo para o atendimento com o dermatologista (hospital X), nove dias após a consulta na ESF.

O hospital X o diagnosticou com alopecia total e pediu o retorno de Teo para o especialista do município. Não houve alternativas de tratamento indicadas.

O médico especialista do município não se mostrou inclinado ao atendimento, dizendo que não tratava de alopecia total, mas também não apresentou alternativas para o atendimento.

Paula, sem ter mais opções, dirigiu-se ao setor de agendamento da Secretaria de Saúde. Explicou a situação à funcionária que a atendeu e rapidamente uma consulta dermatológica foi agendada para Teo no hospital Y.

A ACS Mari entregou o encaminhamento já agendado à Emília. Apesar de já ter a consulta agendada, Emília relatou que não iria ao hospital Y, pois não queria correr o risco de não ser atendida novamente e que trataria do caso do filho por si mesma, dizendo que iria à Secretaria de Saúde tratar com um "cargo superior" para que resolvessem a questão da consulta.

Assim, Teo, apesar de apresentar queixas, como não querer ir à escola e baixas notas escolares, ainda estava sem suporte psicológico até o momento em que o fluxograma foi realizado, ou seja, seis meses após perder todos os pelos do corpo.

\section{A saída}

Paula relatou que, depois desses acontecimentos, perdeu a credibilidade e o contato com Emília, e que isso se intensificou depois que o 
"cargo superior" conseguiu atendimento (hospital Z) para Teo, suprimindo, assim, totalmente a autonomia da ESF em coordenar o cuidado. A enfermeira também não tentou alternativas de aproximação. Complementar a isso, Paula, com ar de cansaço e desapontamento, referiu-se a seus superiores como "muito políticos", o que atrapalhava significativamente o cuidado prestado à população.

Mari também relatou que Emília havia dito que não iria mais à ESF, pois "lá não se resolvia nada" e se afastou do serviço. Contou também que Teo havia sido triado para a consulta no Hospital $\mathrm{Z}$ com espera de um ano.

Sumariamente, Teo saiu do serviço de saúde com o urologista agendado, especialidade sem espera prolongada.

\section{O encontro com o "cargo superior": uma nova entrada?}

O "cargo superior" na Secretaria de Saúde também recepcionou Emília e Teo, não necessariamente ao nível primário de atenção (ESF), mas como uma "ponte" no atendimento ao nível secundário (ambulatorial) de saúde quando os encaminhou para o serviço de especialidades.

\section{O encontro com a pesquisadora: uma nova entrada?}

Foi nesse momento do processo de atendimento de Teo (quando houve sua saída) que a pesquisadora aproximou-se da ESF para realizar a pesquisa. Após elucidação do tema que supostamente seria pesquisado, a enfermeira sugeriu que Teo pudesse participar da pesquisa, e disse: "Mas temos um problema, acho que a mãe de Teo está brava comigo" e contou a história da saída de Teo e de sua mãe do serviço de saúde.

Depois de um diálogo pensativo entre a profissional e a pesquisadora, considerou-se que a reaproximação com eles seria mais adequada do que solicitar novamente seu retorno. Assim, uma visita domiciliar com a presença da ACS Mari poderia ser um meio de recuperar o vínculo com esse paciente. Essa visita poderia também se transformar numa oportunidade para direcionar o olhar cuidador a toda a família, que tinha questões de várias ordens: gravidez na adolescência, um membro acamado com problemas neurológicos e mentais (a irmã de Teo), muitos filhos e uma situação socioeconômica delicada, segundo a ACS.

\section{A recepção}

Ao encaminhar-se para o local, foram convidadas a entrar e sentar-se. Paula perguntou como
Teo estava e disse que gostaria de vê-lo. Minutos depois Teo apareceu suado e agitado, vestia uma bermuda abaixo do joelho, camiseta larga e um boné grande que praticamente escondia todo o seu rosto e, por isso, quase não se enxergava sua face. Teo não olhava diretamente nos nossos olhos, falava num tom muito baixo e de cabeça baixa e parecia querer esconder-se do mundo.

Teo aproximou-se, cumprimentou a todos, sem olhar nos olhos, e sentou-se no sofá, de onde não saiu em nenhum momento.

Além disso, Emília contou que certo dia abriu o caderno de Teo e ficou surpreendida, não sabia o que estava acontecendo com seu filho, pois todo o caderno de exercícios estava em branco e suas notas estavam muito baixas; ele também não gostava de ir mais para a escola, ia "empurrado".

A enfermeira Paula sugeriu marcar uma consulta de enfermagem na ESF, pois lá poderia atendê-la com Teo e conversar sobre as necessidades da família, e Emília prontamente concordou.

\section{Decisão}

Consulta de enfermagem com enfermeira na ESF; porém, Teo não compareceu, somente a mãe.

\section{Cardápio}

Paula perguntou à Emília como ela achava que Teo estava lidando com a alopecia e ela explicou que, além das notas estarem baixas, inventava “desculpas" para não ir à escola, como dores de cabeça, estômago ou estar doente por algum motivo. Teo contava à mãe que os meninos “zoavam” dele o tempo todo pela falta de pelos no corpo. As queixas chegaram a tal ponto que Emília teve que ir à escola conversar com a diretora, o que pareceu atenuar o problema "do não ir" à escola e diminuir as queixas.

Paula contou que, como Teo não compareceu, pouco foi feito em relação a ele, porém pediu à Emília para acompanhá-lo em consultas de enfermagem periódicas na intenção de ampará-lo em suas necessidades diversas e também entraria em contato com a psicóloga do município para tentar vaga em sua agenda, que sempre estava lotada. Os cuidados se estenderam para a família de modo geral (ginecologia, puericultura, assistência social e assistência de enfermagem).

\section{Saída}

Ainda não havia acontecido a saída de Teo do atendimento na ESF, já que a enfermeira entendeu que ele necessitava de cuidados contínuos, principalmente de suporte emocional. Cita-se 
a enfermeira, pois os demais profissionais, com exceção da ACS Mari, pareciam não ter tomado decisões ativas no sentido de oferecer algo para além do prescritivo a Teo. Além disso, a equipe não citou momentos de discussão de casos, nem para Teo nem para os demais usuários da unidade.

Apesar da ausência de um plano terapêutico que atendesse às necessidades de Teo, ao longo da confecção do fluxograma, a equipe pôde visualizar o extenso tempo de espera de Teo para conseguir atendimento e se surpreendeu. $\mathrm{O}$ médico João chegou a dizer, com expressão de preocupação, para a enfermeira: "Nossa, Paula... precisamos tratar desta alopecia aqui".

\section{Decisão}

Teo permanece na ESF.

\section{Cardápio}

Após visualizar os passos de Teo na rede de atenção à qual ele pertencia, a equipe observou poucos cuidados efetivos à saúde do adolescente, de tal modo que esse cardápio foi produzido ao final do fluxograma pela equipe.

Algumas decisões foram tomadas, tais como: tentar tratar da alopecia de Teo na ESF, mas também não descartaram retomar novamente o contato com o especialista do município a fim de ter mais informações sobre o caso e tratamento especializado; tecer intersetorialidade com a escola, a fim de que pudessem dialogar com a diretora ou professora, uma vez que o bullying sofrido por Teo estava afetando sua saúde mental e, consequentemente, seu desempenho escolar, considerando também que a educação em saúde relativa ao bullying entre estudantes nas escolas era necessária; oferecer cuidados a toda a família de Teo, por meio do atendimento de enfermagem e domiciliar, levando em conta gravidez na adolescência, o suporte à Emília com a enteada que estava acamada e necessitava de cuidados neurológicos e mentais; providenciar atendimento psicólogo para Emília e Teo; e, finalmente, criar alternativas de lazer e distração para Teo, como, por exemplo, aulas de bateria, que foi algo citado por ele nas entrevistas realizadas com a pesquisadora (que aconteceram concomitantemente à atividade do fluxograma).

Tal indicação fez a equipe lembrar do auxiliar de enfermagem Daniel, de outra equipe dessa mesma ESF que atendia Teo, que era baterista de uma banda e, por isso, um possível contato para que a equipe pudesse ofertar outras formas de cuidado a Teo.

\section{Quantas lógicas de cuidar existem?}

\section{O cuidado atento: a Agente Comunitária de Saúde}

A equipe de saúde participou da construção do fluxograma de forma heterogênea. Parte dos profissionais participou mais ativamente e outros menos, de modo que dobrando a atenção às ações da ACS Mari. Do início ao final da atividade, a percepção panorâmica da profissional à saúde de Teo fazia emergir detalhes do atendimento que colaboraram para uma produção rica e criativa no fluxograma.

Desde a entrada de Teo, a ACS Mari coloca em evidência o sofrimento do adolescente pela falta de pelos no corpo, mas, principalmente, pelo afetamento de sua saúde mental por ser vítima de bullying. Há de se considerar também o modo prestativo, ágil e resolutivo de levar informações e entregar os encaminhamentos (que foram muitos) à mãe de Teo, já que esta morava longe da unidade de saúde (e na área também não havia transporte público com frequência). Além disso, cabe ressaltar a forma como mediou conflitos entre a unidade de saúde e a mãe de Teo, quando esta queria romper o vínculo com o serviço, e a maneira como restabeleceu tal vínculo com a mãe de Teo quando a enfermeira sugeriu uma visita domiciliar à família do adolescente; por último, e principalmente, deve-se levar em conta a riqueza de informações sobre o adolescente Teo e todas as suas dificuldades emocionais decorrentes da alopecia, ou seja, com um olhar "vibrante" aos emergentes problemas do garoto. A profissional parecia atuar em uma malha invisível de fazeres "pouco vistos" e fundamentais para que ele recebesse um cuidado atento, contínuo e que fazia a "roda da engrenagem" girar.

De acordo com Merhy ${ }^{16}$, o profissional pode tecer suas redes de produção de cuidado por modos singulares e "operando" (no gerúndio) de saber-fazer, que permite o novo, que se coloca à prova e resiste a modos de fazer já postos e dados. Esse modo de fazer criativo e inventivo traduz o "autogoverno" do profissional e seu trabalho vivo em ato, o qual está sempre em movimento, sempre fazendo, instituindo, criando e recriando, modificando, transformando, conturbando e até invertendo certas lógicas consolidadas e instituídas de trabalho.

Nesse sentido, a esquizoanálise trabalha na perpectiva de que o espaço institucional pode ser composto por forças intituintes e instituídas. A primeira diz respeito à produção do novo e não se submete à organização ou a níveis hierárqui- 
cos, tampouco à reprodução ${ }^{19}$. Já a segunda trabalha para a reprodução e antiprodução, manutenção da estabilidade e regulação de padrões ${ }^{19,20}$.

Levando em consideração esses conceitos, a ACS Mari, em seu traçado laboral, da ordem do "dando", e instituinte, em todo o processo de cuidar, quebrava os modos de operar doença-centrado e especializado, pois enxergava Teo para além do corpo biológico e da alopecia, identificando seu sofrimento emocional por ser vítima de bullying escolar. Complementar a isso, resistia às linhas de captura atendimento-fragmentado quando em sua fala expressou um saber-olhar refinado de tudo o que acontecia na vida daquele usuário desde que seus pelos caíram, configurando um cuidado longitudinal e contínuo ao adolescente dentro do seu conjunto de afazeres assistenciais.

\section{$O$ cuidado desarticulado e cansado:}

\section{fluxo enfermeira-médico-especialista}

Além do trabalho vivo em ato, o profissional de saúde também pode operar em linhas de cuidado que configuram um atendimento menos criativo e engessado, menos produtor do novo ${ }^{17}$. Tais linhas de cuidar não necessariamente são negativas ou ruins, porém já não estão acontecendo em ato, assim, tornam-se instituídas e pouco flexíveis. Desse modo, podemos considerar e nomear tais lógicas dadas e cristalizadas do trabalho, as quais não mudam e estão estagnadas nos modos como se estrutura o serviço e até mesmo como trabalham os profissionais, em trabalho morto ${ }^{16}$.

Nesse espaço multiprofissional, micropoderes pulsavam a todo tempo. Linhas instituintes do relacional e afetivo operavam, mas eram constantemente capturadas por um modo de fazer normatizado no atendimento especializado preso aos níveis intelectuais (grau de formação acadêmica), minorando o trabalho manual e relacional e assim refletindo um modo fragmentado de fazer saúde. Um exemplo disso são algumas das ações de trabalho da ACS que, apesar de seu alto grau de liberdade em assistir Teo, ora opera singularmente, como quando identifica o sofrimento de Teo, ora é capturada pelo fluxo informação-enfermeira-médico-especialista, cujo trabalho se detém a levar a informação para a enfermeira, em que perde potência, afetamento e, inclusive, a própria informação (do bullying), que não foi abordada no atendimento de enfermagem e médico.

A enfermeira capturada pelo cuidar tradicional biologista surdeou, bloqueou-se para o inventivo, interrompendo uma infinidade de pos- sibilidades de cuidar e intervir na situação. Diz-se surdeou, pois ouviu, mas não escutou (internalizou/considerou) a preciosa informação trazida pela ACS Mari acerca do sofrimento escolar de Teo, em que o bullying apareceu, mas continuou imperceptível, esmagado pelo saber centrado no corpo e no diagnóstico. Tal posicionamento profissional parece contribuir para uma produção de angústia, já que não alivia o sofrimento, estende a busca de amparo para outro profissional e desconsidera outras possibilidades de fazer saúde ao adolescente, traduzindo-se em um atendimento inicial árido e descompassado ${ }^{21}$.

No processo de construção do tracejado do adolescente, o médico João parecia estar à margem do atendimento e não participou tão ativamente, pois pouco sabia sobre o que se passava na vida de Teo. O cuidado desse profissional também se traduziu neste estudo como reprodutor das práticas biologicistas e fragmentadoras, quando foca somente o aspecto físico do adolescente, desconsiderando as dimensões psicossociais dos usuários em seu atendimento.

Incluem-se, nesse conjunto, questões sociais e de moradia, que reforçam ainda mais a inviabilidade de tantos encaminhamentos, já que Teo residia a $60 \mathrm{~km}$ do local das especialidades (na cidade de São Paulo) e tal ação por parte do profissional resultou em gastos para a família, além de cansaço físico e mental. Soma-se a isso a assistência descompassada, que também é reforçada pela rede assistencial do munícipio, em que a impossibilidade (resistência intrigante) do especialista do munícipio em atender Teo intensifica a cansativa busca por acesso à saúde, levando-o para fora de seu local de moradia.

De acordo com Caçapava ${ }^{22}$, a comunicação e o ânimo dos intercâmbios entre a equipe são algumas das ferramentas mais potentes de cuidar, pois são produtoras de confiança e coesão, resultados da troca de informações, de identificações das mesmas experiências não sabidas pelo outro, do compartilhamento das dúvidas, das decepções e da impotência.

Em suma, esse cenário unidisciplinar, de pouca comunicação e restrito em fazer saúde, produzia encontros “tristes” não somente com os usuários, mas também com os trabalhadores. Tal forma de conduzir o cuidado estampava o cansaço visível dos profissionais em seu espaço laboral, reproduzindo um agir cheio de lamúrias que minava as possibilidade de encontros potentes e afetuosos $^{23}$. Segundo Guattari e Rolnik ${ }^{24}$, o produzir é irrompível com o desejo, ou seja, pouca produção se tem quando pouco se deseja. 
O desejo de cuidar de Teo integralmente estava reduzido, tanto que não aconteceu. A atenção ao adolescente para além da perspectiva do corpo, considerando o cuidado da sua produção de subjetividades, foi possível em vários espaços, porém não ocorria, continuava suspenso, impalpável.

A impressão era de que o cuidado a Teo passava por uma peneira, ou um funil, em que a ACS vinha com um aporte riquíssimo de informações, "passava” para a enfermeira, que filtrava o bullying e era tomada pela "queda de pelos" no corpo e pela "urgência” (com alguma demonstração de afetamento, produzindo vínculo com Teo e sua mãe); esta "passava” para o médico, para quem o problema do adolescente se traduzia em alopecia e criptorquidia (com pouco ou quase nenhum afetamento ou vínculo); este "passava" para o especialista do munícipio, que "passava" para o Hospital X, que "passava” para a ESF novamente, que encaminhava para o Hospital Y, que "passava" para a mãe de Teo, que não "passava" para ninguém e tentava resolver por ela mesma.

\section{O cuidado ressignificado: Teo e sua mãe}

Nesse tracejar, protagonizado genuinamente pela mãe de Teo e que estava carregado por um intenso desejo de cuidar de seu filho, algo chamou a atenção: o fator confiança naquelas relações. Tomando emprestados os escritos de Rolnik $^{25}$ sobre o filme Confiança, de Hal Hartley, entende-se que o que o usuário quer do serviço de saúde é primeiramente sentir confiança, uma vez que tal sentimento agiria como linha de fuga para deslocar aquele relacionamento da uniformidade (serializada) e trazê-lo para o território do cuidado contínuo e afetivo. Confiança que abriria rachaduras nesse modelo tradicionalista e criaria outros modos de subjetivação (autônomos/independentes), outros mundos (libertos/inventivos), o amparo na queda e a coragem de cair. Há de se considerar que a confiança seria uma outra força em jogo, que abalaria o processo de fazer saúde da equipe, fazendo-os habitar o território tecido na perspectiva do afeto e colocando-os em espaços de decisão, desejo e vontade de cuidar que resistisse à captura por linhas de homogeneização do cuidado.

Entretanto, o território saúde estava dominado pela perda da confiança, de modo que não seria surpreendente ver que, em alguns momentos, o desenho cartográfico traçado pela equipe de saúde era capturado (positivamente) e despencava para outro território, o protagonizado pelos usuários. Emília produziu outros modos de cuidar de Teo mediatizada pelo sentimento de desconfiança no serviço de saúde. Quando ela desiste da segunda consulta agendada pela enfermeira e produz novas formas de cuidar de Teo, no caso deslocar-se até a Secretaria de Saúde para conversar com o "cargo superior", ela cria outras significações e possibilidades de cuidado.

\section{O cuidado possível:}

\section{a atividade do fluxograma}

Os mapas cartográficos produzidos por Teo e Emília em busca de um atendimento efetivo foram percebidos pela equipe na atividade do fluxograma, de tal forma que tais visibilidades colocaram em questão os modos de cuidar da equipe, fazendo-a refletir sobre seus processos laborais. Sobre isso, a Análise Institucional, referencial norteador deste estudo, alcançou seu objetivo, que é fazer uma autoanálise e autogestão dos processos de trabalho, fazendo emergir possibilidades de produção do novo ${ }^{12}$. O fluxograma dispara perguntas (algumas não verbalizadas) potentes em atuar como dispositivos de denúncia e interrogação do oculto ${ }^{19}$, do velado e do massificado pelos modelos de cuidar tradicionais vigentes. Esses dispositivos - que neste caso expressaram-se pelo olhar atento e interrogador dos participantes para o traçado de Teo - favoreceram o autoquestionamento da equipe ${ }^{18}$. Os profissionais pareciam mastigar algo, e o momento era de deflagração de uma visibilidade indigesta.

Os participantes levaram um tempo para deglutir aquele algo desagradável e se expressavam por meio do não dito, transparecendo inquietação. Porém, como todo dispositivo trabalha pelo não dito e do não sabido, dizibilidades antes não pensadas e não vistas afrouxavam-se e vinham à tona. Utilizando os princípios da esquizoanálise, que têm como prerrogativa ocorrer a "quente"19 (na velocidade e intensidade dos afetos, dialógos e impressões), sentia-se que subjetividades descuidadas que lá estavam no fundo de uma chaleira borbulhavam... e então algumas palavras foram ditas pelo médico: "Paula, precisamos fazer alguma coisa!".

Perceptivelmente, ao se depararem com o tempo prolongado de espera de Teo por atendimento e a ausência de um cuidado efetivo ao longo daquele processo, a equipe pareceu ter percebido algo que estava invisível, abafado pelos afazeres automatizados do cotidiano. $\mathrm{O}$ olhar cuidador ganhou certo espaço ao final do fluxograma. Entretanto, alguns profissionais (dois, o médico predominantemente e a enfermeira em 
grande parte do tempo) quase não ultrapassaram o grande muro do diagnóstico de alopecia, que estava ali sombreando outras necessidades de Teo, como as dificuldades de ir à escola, a tristeza e o bullying.
Apesar disso, ao final do processo de elaboração do fluxograma, todos os participantes, alguns mais, outros menos, encontraram outras possibilidades de cuidado a Teo (Figura 2), para além do corpo biológico. A música e a intersetorialidade

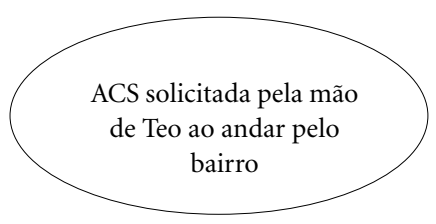

Encaminhametos externos: dermatologia e urologia do município
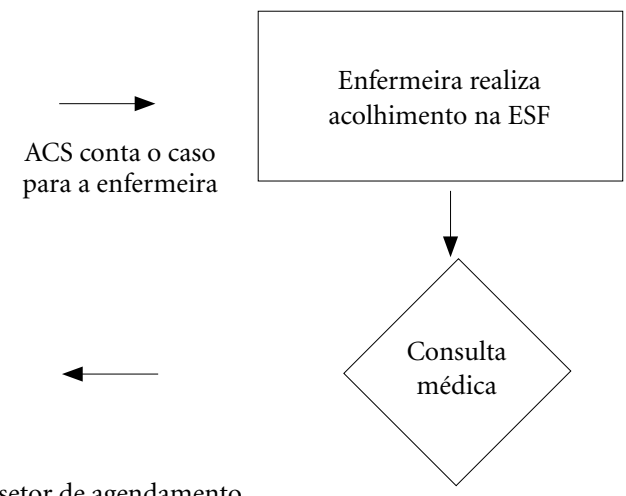

Enfermeira pelo setor de agendamento pede que encaminhamento de Teo seja agendado para o Hospital $\mathrm{X}$ de referência

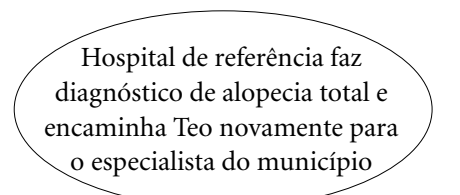

$$
\text { . }
$$

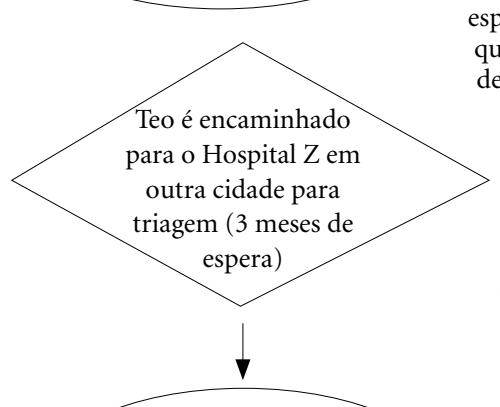

Enfermeira faz visita domiciliar (com pesquisadora) para reatar vínculo por ela considerado perdido na capital/ retira do município

\section{a}

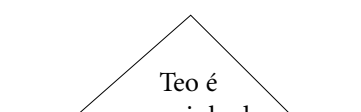

encaminhado

para o Hospital Y

de outra cidade

(realizado pela

enfermeira) conversa diretamente com especialista do município que diz não poder tratar de Teo com seu referido diagnóstico

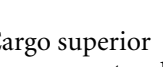
dirige-se ao setor de agendamento

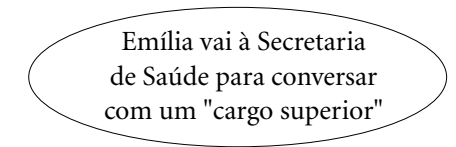

Mãe de Teo (Emília) recusa-se a ir novamente para outro serviço

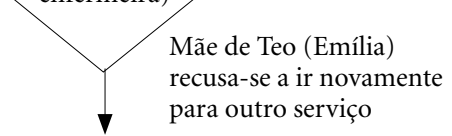

mília vai à Secretaria Saúde para conversar

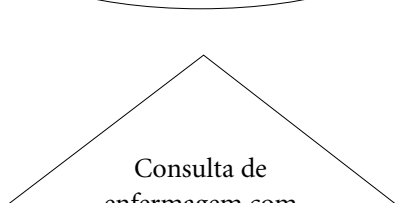
enfermagem com

Teo e Emília é agendada

Produção da atividade do Fluxograma com a equipe:

Aproximar-se da escola

Apoio emocional para Teo (psicólogo)

Acompanhamento pela ESF

Atender melhor as demandas da família
Teo não comparece na consulta, somente sua mãe e o irmão mais novo

Figura 2. Fluxograma analisador.

Fonte: Elaboração própria. 
com a escola surgiram como canais para a produção de subjetividades alegres, libertas e criadoras de outros mundos, pois retiraria Teo daquele território-diagnóstico centrado, daquele espaço -alopecia em que só o que se via era a doença e não o adolescente.

\section{Considerações finais}

O desfecho da atividade possibilitou olhar para a vida de Teo em si e não somente para a patologia. Todavia, de modo geral, o cuidado ofertado não alcançou a dimensão do sofrimento psíquico decorrente do bullying escolar. A alopecia tão visível e inquietante (principalmente para o profissional) rouba a cena e se faz protagonista na vida do adolescente. Complementar a isso, a burocratização e fragmentação da assistência prestada rompe com qualquer possibilidade de cuidado contínuo e longitudinal. Ademais, a equipe pouco trabalhou na perspectiva do coletivo e, ainda assim, e paradoxalmente, foi na "contramão", dando passagem para linhas potentes de produção intensiva de sofrimento.

Assim, considera-se que a contribuição desta pesquisa foi de, através da utilização da cartografia e do fluxograma, possibilitar a visualização dos modos de operar e produzir cuidado de uma equipe de saúde a um adolescente vítima de bullying. Alguns elementos ficaram sobressalentes e ilustraram a existência de uma frágil rede de suporte à saúde do adolescente (esteja ele envolvido ou não com a violência), que foram: as estratégias de cuidado e atenção desarticuladas entre os níveis de atenção em saúde, atenção básica, ambulatorial e hospitalar; a reduzida comunicação entre os profissionais de um mesmo grupo de trabalho; e a inexistente atenção à dimensão psicossocial, somada a pouca resolutividade em dar resposta à condição do diagnóstico médico (alopecia). Esses elementos caracterizam uma rede que não oportuniza o cuidado integral e resolutivo, logo, indicam a urgente e adequada implementação das Políticas Públicas vigentes, no sentido de aperfeiçoar a formação dos serviços e articular as estratégias de atenção direcionadas à saúde do adolescente.

Em relação ao bullying, ficou evidente a frágil percepção dos profissionais em concebê-lo como um risco à saúde do adolescente. Acredita-se que o fator cansaço, que pode ter sido proveniente da forma como se estruturam os processos de trabalho da equipe (pouca comunicação e verticalização da assistência), colaborou para a produção de um cuidar desatento e negligente. Atentar-se a esta complexa problemática exigiria sondagem detalhada sobre o ocorrido (O que ocorreu? Como ocorreu? Onde ocorreu? Quem o fez? Quais são os sentimentos do adolescentes? Quais são seus pontos de suporte?) e tempo de escuta. Essa sondagem e escuta resultariam em um cuidar atento às singularidades dos jovens, bem como às suas experiências, o que daria passagem ao protagonismo e valorização da vida e criaria espaços comuns de co-construção do cuidar com a escola.

Considerando a significativa ocorrência do bullying nas escolas brasileiras ${ }^{3-5}$, suas consequências devastadoras à saúde dos jovens ${ }^{1,2}$, assim como a dificuldade destes em verbalizar que são alvos de tal agressão ${ }^{7}$, saber identificá-lo e estar preparado para manejá-lo é fundamental para a cessação do ciclo de violência. Destaca-se que a atenção primária, no território de passagem do adolescente, poderia contribuir tanto para a identificação do bullying quanto para instrumentalizar a escola e a família para lidar com a agressão. Entretanto, seus profissionais devem ser devidamente treinados e estar atualizados para lidar com esse tipo de violência, que é potencialmente prejudicial à saúde física e mental dos adolescentes.

\section{Colaboradores}

PL Pigozi trabalhou na concepção, análise, interpretação dos dados, redação do artigo e aprovação da versão a ser publicada e AL Machado trabalhou na análise, na interpretação dos dados e na versão a ser publicada.

\section{Agradecimentos}

Agradecemos à CAPES (Coordenação de Aperfeiçoamento de Pessoal de Nível Superior) pela concessão da bolsa durante o desenvolvimento deste estudo. 


\section{Referências}

1. Smith PK, Sharp S, editors. School bullying: Insights and perspectives. London: Routledge; 1994.

2. Smith PK, Morita Y. Introduction. In: Smith PK, Morita J, Junger-Tas J, Olweus D, Catalano R, Slee P, editors. The nature of school bullying: A cross- national perspective. New York: Routledge; 1999. p.1.

3. Moura DR, Cruz ACN, Quevedo LA. Prevalência e características de escolares vítimas de bullying. J Pediatr 2011; 87(1):19-23.

4. Fisher RM. Bullying escolar no Brasil: relatório final. São Paulo: CEATS/FIA; 2010.

5. Malta DC, Porto DL, Crespo CD, Silva MMA, Andrade SSC, Mello FCM, Monteiro R, Silva MAI. Bullying em escolares brasileiros: análise da Pesquisa Nacional de Saúde do Escolar (PeNSE 2012). Rev Bras Epidemiol Suppl Pense 2014; 17(Supl. 1):92-105.

6. Mello FCM, Silva JL, Oliveira WA, Prado RR, Malta DC, Silva MAI. A prática de bullying entre escolares brasileiros e fatores associados, Pesquisa Nacional de Saúde do Escolar 2015. Cien Saude Colet 2017; 22(9): 2939-2948

7. Lopes Neto, AA. Bullying: saber identificar e como prevenir. São Paulo: Brasiliense; 2011.

8. Yen CF, Yang P, Wang PW, Lin HC, Liu TL, Wu YY, Tang TC. Association between school bullying levels/ types and mental health problems among Taiwanese adolescents. Compr Psychiatry 2014; 55(3):405-413.

9. Smith PK. Understanding school bullying: Its nature and prevention strategies. London: Sage; 2014.

10. Lisboa CSM, Wendt GW, Pureza, JR. Mitos e fatos sobre o bullying: Orientações para pais e profissionais. Novo Hamburgo: Sinopsys Editora; 2014.

11. Brasil. Portaria no 2.436, de 21 de setembro de 2017. Aprova a Política Nacional de Atenção Básica, estabelecendo a revisão de diretrizes para a organização da Atenção Básica, no âmbito do Sistema Único de Saúde (SUS). Diário Oficial da União 2017; 21 set.

12. Barembllit G. Compêndio de análise institucional e outras correntes: teoria e prática. Rio de Janeiro: Rosa dos Ventos; 1992.

13. Alvarez J, Passos E. Cartografar é habitar um território existencial. In: Passos E, Kastrup V, Escóssia L, organizadores. Pistas do método cartografia: pesquisa-intervenção e produçãoo de subjetividade. Porto Alegre: Sulina; 2009. p. 131-149.

14. Passos E, Barros RB. A cartografia como método de pesquisa intervenção. In: Passos E, Barros RB, Kastrup V, Escóssia L, organizadores. Pistas do método da cartografia: pesquisa-intervenção e produção de subjetividade. Porto Alegre: Sulina; 2009. p. 17-31.
15. Barros LP, Kastrup V, organizadores. Cartografar é acompanhar processos. In: Passos E, Kastrup, V, Escóssia L. Pistas do método da cartografia: pesquisa-intervenção e produção de subjetividade. Porto Alegre: Sulina; 2009. p. 52-75.

16. Merhy EE. Em busca do tempo perdido: a micropolítica do trabalho vivo em saúde. In: Merhy EE, Onocko $\mathrm{R}$, organizadores. Agir em saúde: um desafio para o público. São Paulo: Editora Hucitec; 2002. p. 71-112.

17. Pelbart PP. A vertigem por um fio: políticas da subjetividade contemporânea. São Paulo: Iluminuras; 2000.

18. Franco TB. Fluxograma descritor e projetos terapêuticos para análise e serviço de saúde, em apoio ao planejamento: o caso de luz (MG). In: Merhy EE, organizador. O trabalho em saúde: olhando e experienciando o SUS no cotidiano. São Paulo: Hucitec; 2003. p. 161-198.

19. Baremblitt G. Compêndio de análise institucional e outras correntes: teoria e prática. $6^{a}$ ed. Belo Horizonte: FGB/IFG; 2012.

20. Kastrup V, Passos E. Cartografar é traçar um plano comum. In: Passos E, Kastrup V, Tedesco S. Pistas do método cartográfico: a experiência da pesquisa e o plano comum. Porto Alegre: Sulina; 2014. p. 15-41.

21. Lage AMD, Moura LR, Horta NC. Abordagem ao Adolescente e ao Jovem na Atenção Primária. In. Souza MCMR, Horta NC. Enfermagem em saúde coletiva: teoria e prática. Rio de Janeiro: Guanabara Koogan; 2012. p. 213-228.

22. Caçapava JR. A Produção Do Cuidado Em Saúde Mental Na Atenção Básica À Saúde: Um Olhar Dos Trabalhadores Sobre O Acolhimento [dissertação]. São Paulo: Universidade de São Paulo; 2008.

23. Deleuze G. Espinosa, filosofia prática. São Paulo: Escuta; 2002.

24. Guattari F, Rolnik S. Micropolítica: cartografias do desejo. 11 $1^{\mathrm{a}}$ ed. Petrópolis: Vozes; 2011.

25. Rolnik S. Hal Hartley e a ética da confiança. Trafic. Révue de Cinéma 1994; 12:104-114.

Artigo apresentado em 30/10/2017

Aprovado em 23/05/2018

Versão final apresentada em 25/05/2018 
